\title{
The male role in cervical cancer prevention and transmission: Representation of subject positions in South African press reports (1998-2014)
}

\begin{abstract}
Cervical cancer (CC) media coverage neglects mention and interrogation of the role of men in sexually transmitting the virus linked to CC. Newspapers, in their public role of engaging with social debates, unlike other media forms, might be expected to interrogate misconceptions of CC. This study sought to analyse how male persons are represented in newspaper reports of CC. Using the discursive analytic tool of subject positioning, South African newspaper reports of CC were analysed. The findings revealed five categories of subject positions with male persons serving as protagonists who interact with subjects in the remaining four categories. In the male subjects' category, the unaccountable man and circumcised saviour were the most commonly occurring positions. Reportage, however, also covered male positions traditionally marginalized or excluded from public and mainstream health campaigns, and the most pertinent of these were labelled as the sextalk son and the boy saviour. CC should be conceptualized not merely as a health issue faced by individual women, but as a social issue with a need for increased public visibility of the male role in transmission and prevention.
\end{abstract}

Developing countries have the highest rates of cervical cancer (CC), the most commonly occurring cancer among South African (SA) women (Denny, 2006). A significant causal association is found between $\mathrm{CC}$ and repeated human papillomavirus (HPV) infections over time (Dillner \& Brown, 2004). HPV can be transmitted from an infected man to an uninfected woman through sexual contact (Denny, 2010). After transmission of oncogenic HPV, CC
Prevan Moodley

Department of Psychology

University of Johannesburg Johannesburg

\section{Lauré de Vries}

Department of Psychology

University of

Johannesburg

Johannesburg

\section{Keywords}

cervical cancer, HPV, male sexual health, poststructural feminism, subject positions 
develops slowly and may be present for several years before symptoms start appearing (Dillner \& Brown, 2004). Thus, even though women carry the burden of the disease, men play a role in transmission of the virus to female partners.

Given the viral cause, HPV vaccines (HPVV) have been introduced as the first truly effective option of preventing HPV and CC. Two vaccines have become commercially available and are known to be safe, immunogenic, and successful (Denny, 2010). Vaccines require administration prior to infection, thus before sexual debut (Denny, 2010). The optimal age for girls to receive HPVV is around 11 and 12 years of age. Gardasil is approved for use in both males and females between the ages of 9 and 26 (Shi et al, 2007; Balachandran, 2011). Cervarix is approved for males and females between 13 and 26 years (Casciotti et al, 2014). Both vaccines require three dosages to be effective (Dunne \& Markowitz, 2006). Vaccinating girls and boys has been estimated to significantly decrease the prevalence of HPV (Lowndes, 2006).

The SA government launched a national vaccination campaign aimed at Grade 4 schoolgirls in March 2014 (HPCSA, 2014). The African context, however, presents problems (Okonofuya, 2007). These include high costs and the potential of vaccinations to undermine the importance of secondary screening. Focus groups in both Ohio Appalachia and SA worried that the HPVV may give the incorrect message if children interpreted being vaccinated as permission to engage in sexual activities (Francis \& Katz, 2013). In contrast, another study (Katz et al, 2013) found unique promoters for HPVV in SA. This qualitative study, conducted with 77 adolescents and caregivers in Soweto, investigated the reasons for vaccine uptake (Katz et al, 2013). The unique reasons were not directed at CC prevention. Reasons included single-headed household caregivers regarding vaccination both as a way to deter children's sexual activity and a harm-reduction intervention against STIs for girls who were vulnerable to sexual abuse, rape, and age-discordant relationships. The vaccine, in this way, enabled control for girls over their sex lives. Adolescents, rather than caregivers, in a context of poverty, engaged in decision making about taking the vaccine (Katz et al, 2013).

Even though boys should be vaccinated, HPVV has been (publicly) labelled the "girl vaccine" (Mishra \& Graham, 2012: 59). Even within dissemination of medical knowledge, the male role in CC is hidden. A striking example is a 2015 editorial (Botha \& Richter, 2015 ) in the South African Medical Journal that argues for girls needing vaccination without mention of the male role. From a critical health perspective, this information normalizes the non-involvement of men. Furthermore, marketing is framed within cancer prevention, avoiding mention of the connection to STIs which will then implicate heterosexual partners (Mishra \& Graham, 2012; Davies \& Burns, 2014). Nevertheless, a 
recent intervention study of social marketing strategies found that preteen boys are $34 \%$ more likely to get vaccinated in an intervention region compared to boys in regions of no intervention (Cates et al, 2014). However, representation in the media has been gendered because programmes and media coverage focus on girls and women (Giuliano, 2007; Thompson, 2010).

The gender selectivity is consistent with analyses within medicalization theory. CC vaccinations are part of the broader control of the body, wherein everyday social processes in modern societies become increasingly associated with medicine, health, and disease (Lupton, 1997). The female body, constantly portrayed as a site in need of restoration and modification, is the primary target of the medicalization phenomenon (Vardeman-Winter, 2012). Technology and the internet add to medicalization work, creating biomedicalization, a concept that refers to the everyday mode wherein bodies become reconfigured through the biological, medical, and media network (Vardeman-Winter, 2012). Increased biomedicalization of the female body has occurred because the HPVV was initially marketed and administered only to bodies that contained an innate female organ (Mishra \& Graham, 2012).

When the role of men in heterosexual transmission of HPV is under-acknowledged and when HPV is regarded singularly as a female problem, young girls and women extract from the media and health campaigns 'rules' for the medical functioning of their bodies (Vardeman-Winter, 2012). The medical system, which has included the initial vaccine trials and marketing being focused on girls, delayed or denied male accountability. For example, parents in a national US sample indicated willingness to have their adolescent sons vaccinated but had not done so because their healthcare providers had not recommended it (Donahue et al, 2014), indicating medical practitioners were avoiding talking about boys being vaccinated and reinforcing the myth via biomedicalization that HPV should only be talked about in connection with female reproductive health. Similarly, Canadian nurses celebrated the vaccine within the frame of $\mathrm{CC}$ and appropriate feminine performativity (Mishra \& Graham, 2012).

This gendering of the vaccine and the exclusion of boys are even more overt in SA. Many nurses, doctors, female community members, and policymakers were against immunizing boys in SA, with costs and logistics presented as reasons (Harries et al, 2009). When interviewed, one physician was not optimistic that GPs could engage in vaccine awareness for boys unless they had interests in women's health. Respondents believed that vaccine opposition is countered when the vaccine is marketed for a female disease, rather than when it is framed within sexual behaviour. This moralistic construction of excluding talk about sex and sexual transmission of HPV is problematic. The male role in the transmission and prevention of CC gets socially erased. Adverts 
exclude male persons from decisions in sexual health (Davies \& Burns, 2014). Instead, health promotional information constructs females simultaneously as being at risk and responsible for prevention (Charles, 2014; Davies \& Burns, 2014). The male role in CC, through transmission of HPV, has been so absent that in one survey of 980 men in a "township" in SA, no man provided information that HPV can cause CC, attesting to lack of knowledge about CC amongst the particular population (Maree et al, 2011). Thus, men's lack of knowledge implies a threat of HIV infection for themselves and their partners (Maree et al, 2011).

Responsibility has, therefore, been framed in gendered ways in media campaigns for HPV prevention. Televised US Gardasil advertisements implied a postfeminist ethos of choice in the marketing of the vaccine, with imagery indicating women as powerful, successful, and happy (Branson, 2012). An audience-reception analysis of a Gardasil campaign's images of beauty and physical activity also found discursive preference for vaccinated girls as empowered and responsible while denying the role of sex in HPV transmission (Vardeman-Winter, 2012). This has been called a form of neoliberal governmentality, targeted at the health of particular citizens (Charles, 2014), but which contains values for persons who qualify as 'good' citizens. Promotional artefacts appealing to postfeminist notions of empowerment and increased agency assume women become responsible citizens (Charles, 2014; Davies \& Burns, 2014) within clear heteronormative signs (Mishra \& Graham, 2012; Charles, 2014). As preferred subjects, these women are positioned as obligated to consent (Charles, 2014).

The focus on women through individual responsibility deflects from the political purpose of vaccination because this ignores social responsibility. Luyten, Engelen and Beutels (2014) question the moral dimensions of justifying HPVV for the female sex. They argue that discrimination occurs on an individual level if public demographics are used to justify selective vaccination. By targeting girls only, girls become stigmatized as responsible and promiscuous. Another moral argument for boys to be vaccinated appeals to sex being equated with intimacy: Luyten et al (2014) argue that boys should be vaccinated because they have sex with girls, and sexual acts symbolize intimacy. The problem with the intimacy argument is that it delegates recreational or casual sex into positions of deviance. This reflects a heterosexist and romanticized bias that boys have a moral duty to be vaccinated because sex is about intimacy and those 'near and dear' to them must be protected. Such a moral argument does not reflect realistic concerns of non-consensual sex in marriage and forms of sex outside of contexts of intimacy. Stanley (2012, para. 7) takes an activist stance about this: "It is not ethical, fair or socially responsible to have a public-health policy that forces men to rely on herd immunity which won't be reached for decades. Let's start vaccinating men now". 
Given the overt genderedness within health promotional materials and educational campaigns for HPVV, this study sought to investigate this focus, asking how this gendering is interrogated in the public sphere and how the invisible sex (boys and men) gets talked about on a social platform. To ask if the social sphere interrogates this requires accessing a platform that goes beyond media aimed at mere education and information dissemination; it means using a media form that actively engages with social debates. Newspapers satisfy this requirement.

Newspapers provide information about health risks and medical breakthroughs, but they also sensationalize this content (Abdelmutti \& Hoffman-Goetz, 2009; Habel, Liddon \& Stryker, 2009). Information in newspapers may originate from sources such as professional and nonprofessional individuals, health groups, academics, organizations, and the government, all trying to convey a particular point to the public (Giles, 2003). Newspapers announce new scientific developments and allow topics to be debated. Through press reports, information about a medical cure or a new medical technology is relayed from the scientific or policy sphere to the lay public. Furthermore, news media are aligned with agenda-setting (Giles, 2003), which is further reinforced when news items are both local and international (Casciotti et al, 2014). Therefore, health information in the media cannot be separated from the political and social contexts in which it arises (Abdelmutti \& Hoffman-Goetz, 2009). Briggs and Hallin (2007) have thus appealed for critical analysis of newspaper health coverage to be directed at intersections of clinical and health practices, including health promotion.

Newspaper articles offer insights into the stories that circulate in a certain social context over a long period of time. Print media is particularly concerned with the development of ideas and can incorporate an emotional tone while adding vivid coverage, unlike televised news that focuses on emotional aspects (Driedger, 2007). Furthermore, news media, as a discursive site, joins with biomedicine to position readers as consumers. Journalists advise patient-consumers in a neoliberal ideology wherein "doctor's orders" are devalued and the trust of medical professionals is subordinated. Thus, news reports about health, in serving a pedagogical function, assign active roles to readers (Briggs \& Hallin, 2007). Briggs and Hallin (2007: 58) state that this new bio-communicability model, which replaces hierarchical patient-practitioner models, changes "scientific facts into moral facts". Furthermore, journalists criticize roleplayers who disrupt flow of health information making subject positions into ethical positions (Briggs \& Hallin, 2007). Given these characteristics that transform newspapers into a social platform that debates and contests ideas, this study selected newspapers to examine how, when including male persons in their reports, these persons are portrayed with reference to CC. 


\section{Conceptual framework}

Given that CC prevention and HPVV are implicated as sexual and gendered phenomena, social models, rather than rationalist or cognitivist models of health, form the analytic framework for this study. Foucault's theory of the body as target of social management and the theory of poststructural feminism contribute to an analysis of the politics of the gendered body. Foucault's (1978) critical model of health and sex posits that knowledge about sex is created and re-created through a network of customs, regulations, and processes that also occur on a macrosocial level. No single biological process can be separated from political elements (Hook, 2004). Foucault's account of governmentality considers both macropower (a broader aspect of power that the state possesses over a group of individuals) and micropower (which involves the acquired subjectivity of people when they direct their own conduct) (Hook, 2004). Simultaneously, various microforms act to support the larger, macroforms of power (Hook, 2004). Biopower, as the most taken-for-granted guise of governmentality, refers to the management of any aspect of life or biological process (Hook, 2004). Health promotion therefore, which directs campaigns at at-risk individuals, has led Peterson (1997) to argue that a risk approach can be seen as another form of governance.

In Foucauldian theory, macrosocial ideas are represented through discourse. Discourses do not represent an absolute 'truth' but shape and enable reality (Jäger \& Maier, 2009). Discourses provide a series of subject positions for people, so in other words, discourses situate people into slots, roles, places, statuses, or ideal images (Wilbraham, 2004). Following a poststructuralist perspective, textual analysis presents the possibility for interrogating these subjects or the formation of these selves (Wright, 2003; Wilbraham, 2004).

Poststructuralism and feminist thinking unite in poststructural feminism, which should not be understood as merely focused on women's liberation, because it analyses how language, cultural practices, and material effects shape both women's and men's subjectivities (Gavey, 1989). Poststructural feminism aims to analyse the socially-specific understandings, thereby creating opportunities for social change by placing focus on oppressive gender relations (Gavey, 1989). Instead of trying to expose an absolute truth, the goal is to disrupt accepted or dominant truths that circulate within a society or social setting (Gavey, 1989), the ideological goal of this study.

Applied to gender, subject positions can either dispute or replicate present gender relations. Discourses create representations which, depicted in the media, are never gender-neutral (Weedon, 1987). The media and medical science, for instance, are social forces, yet subjects may refuse or resist what is being offered. Individuals do not passively accept the positions because choice is possible (Gavey, 1989). Thus, deconstructing 
subject positions exposes power structures (Harper \& Rail, 2011). Images of how a person is supposed to act and behave, rules for conduct that a person must follow, and definitions and meanings of what is natural for a specific person all encompass gendered subject positions (Weedon, 1987). Subject positions are thus avenues for composing individual subjectivity and for offering different levels of power to persons (Gavey, 1989). Power is thus ascribed differentially not only across genders but also within any one version of gender.

In the system of biopolitics, health news specifically produces particular subject positions. Medical facts get presented as stable, yet create differential levels of power and agency to reader-consumers who "are interpellated or hailed in the process - and then position themselves within these constraints, or, less commonly, reject the proffered communicable maps" (Briggs \& Hallin, 2007: 58). Through the concept of bio-communicability, health information is not separated from science, society, and politics, but is directed at various "social positionalities and allocates different types and amounts of symbolic capital for each party" (Briggs \& Hallin, 2007: 58). Briggs and Hallin (2007) thus have illustrated how the analytic of subject positioning is particularly useful when applied to health news communication. In this way, subject positioning allows for an examination of the micropolitics of social life (Papadopoulos, 2008).

\section{Methods}

This article provides an analysis of how male persons are positioned in press reports about CC, which was part of a larger research study (de Vries, 2014). The sample was collected through the Sabinet database. Within the SA News catalogue, three keyword combinations were used: "CERVICAL CANCER" AND "PREVENTION" (187 articles), "CERVICAL CANCER" AND "VACCINE" (131 articles), and "CERVICAL CANCER" AND "SCREENING" (148 articles). Because the focus of the study was framed within the transmission or prevention of $\mathrm{CC}$ and the gendered basis of this in health texts, the preceding keyword combinations were used. The focus was not on HPV because the study is based on the premise that in texts of CC, HPV as an STI is not overtly mentioned, and the study aimed at discovering how, when $\mathrm{CC}$ is mentioned, male sexual transmission is interrogated or debated.

The three sets of search results were checked, repeat items were discarded, and 288 articles remained. A further nine were incomplete or irrelevant. Two articles from non-SA newspapers were also discarded, resulting in 277 articles subjected to content analysis in the main study (de Vries, 2014). For the analysis presented here, the search was narrowed down even further. Out of 277 articles, those explicitly mentioning male persons were selected. This yielded 26 English reports, as presented in Table 1. 


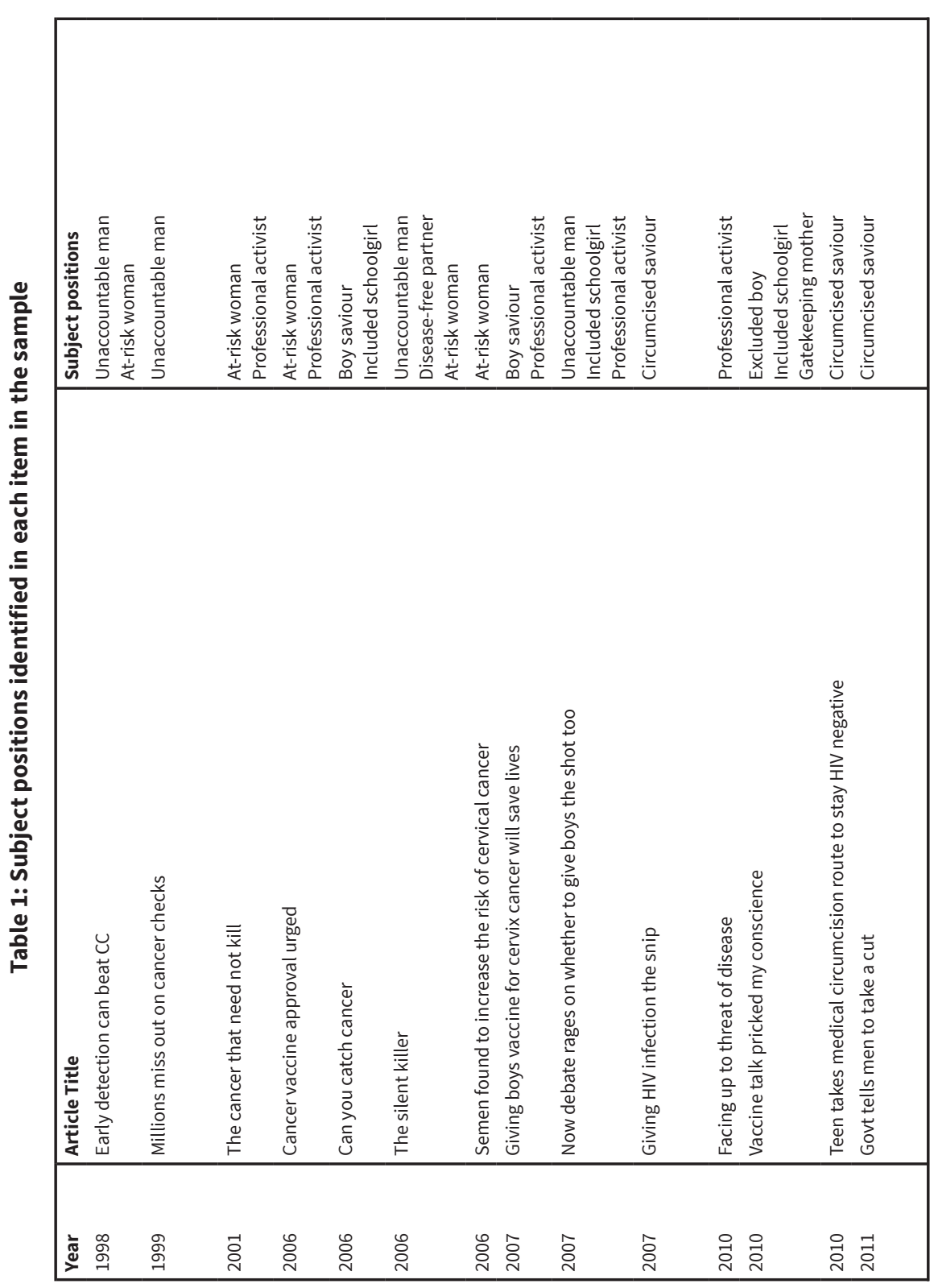

51 PINS [Psychology in Society] 52.2016 


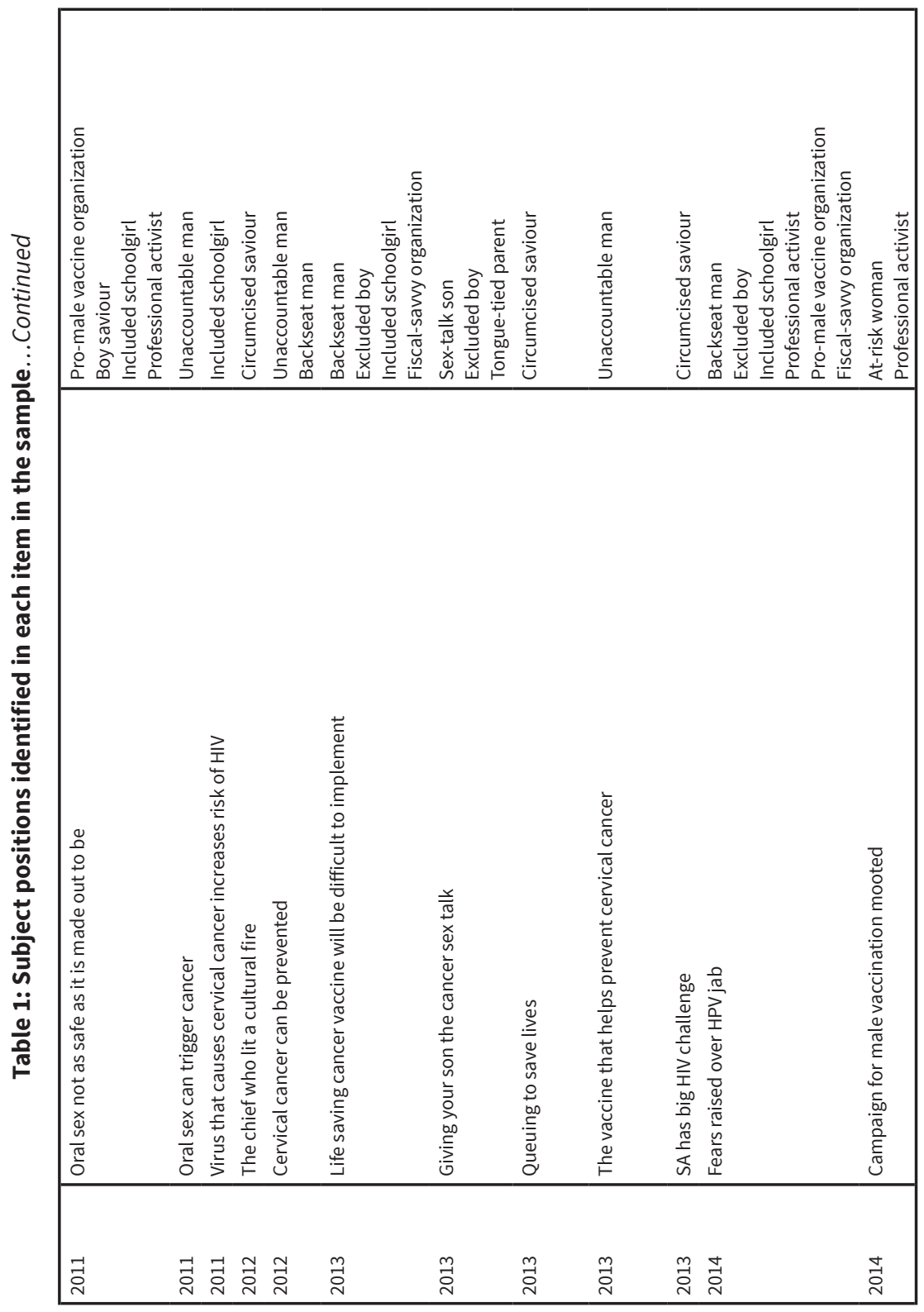

PINS [Psychology in Society] 52 • 2016|52 
Subject positions were used as the lens for interpretive work. In line with this, the subject positions analytic does not require a large sample, because even a single or seemingly trivial text can be analysed as a "surface of emergence" of meanings (Wilbraham, 2004: 498). A key strategy is the identification of roles, statuses, or categories of action which are postulated by discourse and in which people subsequently situate themselves. Roles and identities get configured through intersecting categories of sex, age, gender, and responsibility. The implication of these categories is that they provide subject positions that shape how health prevention acts are adopted. As presented in the conceptual framework, subject positioning is a constituent of subjectivity. In other words, in contrast to mainstream models of psychology, subject positions depict how psychological life is constituted. Thus, discursive practice incorporating analysis of subject positions is a theoretical method (Wilbraham, 2004).

The analytic process began with a thorough reading of the 26 articles. Next, sentences, phrases, or sections referring explicitly to male persons were highlighted and then copied onto a separate document to form a transcript. The third stage encompassed free association. This step was informed by connotations and takenfor-granted ideas. The final stage involved an elaborate investigation of subjects. This was achieved by itemizing subjects, thereafter arguing each subject's roles and responsibilities, and discerning the networks of relationships among subjects (Parker, 1992). Even though the aim was to examine the subject positioning of male persons, positions are never placed in isolation, as they are always related to positions of other persons. Thus, the findings are presented in different categories, with the male persons as the protagonists.

Categories, each with their own set of subject positions, were created. Reliability was achieved by each researcher independently free-associating and establishing categories for the types of subject positions. Both parties then reached agreement on the system to specify types of subject positions. Finally, the network of relationships received elaboration.

\section{Findings and Discussion}

Five categories were identified: male subjects, female risk positions, parents, professionals, and organizations. The first two categories contain positionings wherein action (or inaction) occurs within the bodily transmission and/or prevention of HPV. Thus, male bodies directly implicated in CC formed the core category, and the other categories reflect positionings that, in turn, direct (or misdirect) male responsibility in CC prevention. All frequencies refer to counts within the analysed sample of 26 articles. 


\section{Male subjects}

The male subject is allocated seven distinct positions: the unaccountable man, the disease-free partner, the circumcised saviour, the backseat man, the sex-talk son, the excluded boy, and the boy saviour. Each position plays a particular role (or no role at all) in the prevention of CC

The unaccountable man appears in seven articles. He is likely to "acquire a genital HPV infection at some point" (Graham, 2006), but he is not encouraged to take preventative measures. The sexual actions of this man affect "wives' risk" of CC, thus his recklessness in turn positions the married monogamous female spouse as a victim ("Early detection can beat CC", 1998). He may "never develop any problems" (Malan, 2012b), a description that neutralizes his contribution to CC infection. He is described as being an "equal player" making up "half the equation" in transmission, yet is not targeted by any vaccination campaigns (Mundell, 2007). In these descriptions, this subject is overall a sexually active, heterosexual male portrayed as living and speaking from the masculinist position of sexual freedom. A symptom-free body is linked to few responsibilities of which he may be highly unaware.

In the hegemonic spontaneous and carefree position, the unaccountable man can continue with sexual practices without being subjected to vaccinations or clear-cut guides for action. His own health receives minimal focus because his body is not conceptualized as one in need of fixing or at risk. In Ord's (1999) article from The Daily News, wherein a new cervical spatula is announced, the Pap smear procedure and the results thereof are explained in-depth within the context of the probing typical of a female body examination; yet, men, in the subsection of that article called "Fact File" and misclassified under the subheading of "Cervical Cancer Risk Factors" receive vague mention: "Males with HPV infections should have regular physical examinations" (Ord, 1999). This reference to the male role, apart from being overgeneric, implies two problems: one, information on detecting male HPV infection in the first place is absent; and two, in the context of the article about screening through Pap smears (whether with the imported spatula or the local flexible variety), the male medical examination, surprisingly, is just "regular" without any probing or reference to examination of male genitals.

The representations of men, nevertheless, are not completely free from action in the fight against CC. Two "enlightened" positionings are portrayed when a man assumes a protective role: the disease-free partner and the circumcised saviour. The disease-free partner is an uninfected partner who, mentioned in one article, is portrayed as the 'ideal' partner. A woman can reduce her chances of developing CC by "staying in a long-term, mutually monogamous relationship with an uninfected partner" (Graham, 2006). The heterosexual relationship is framed within the logic of prevention. 
In an even more enlightened role than the unaccountable man, another positioning is taken by the circumcised saviour. Appearing in six articles, the subject's circumcision status simultaneously "keeps the penis clean and free of odour" (Bodibe, 2013), "promotes better hygiene" (Masoetsa, 2011), and protects female sex partners:

"The advantage to women is that there is less incidence of cervical cancer among women who have a partner who is circumcised." (Beaver, 2013)

"Rabbi ... said ... 'Medical studies have shown that women whose sexual partners are circumcised have lower rates of cervical cancer'." (Naran, 2007)

"'So it also helps your wife', Mumena [Zambian clan chief] said. 'Circumcision helps your spouse to be less likely to get cervical cancer, because a man can give a woman his HPV." (Malan, 2012a)

In these quotes, the (circumcised) male body is presented as appropriately modified to guard the (vulnerable) female body naturally at risk. Nevertheless, males seem to be vectors with the woman still the hub of sexual (ill)-health, contributing even further to the idea that HPV is predominantly a female problem onto which health practices need to be aimed. Both the disease-free partner and circumcised saviour heroically act as HPV-free protectors for women who are innately at-risk of HPV and CC. These two positions become personifications of primary health. By acting as a strong preventative barrier, they can promote their partners' chances of surviving a dangerous health threat.

The backseat man, appearing in three press reports, refers (idiomatically) to the positioning of a man, who, within the heterosexist framing of CC, does not play any role in CC prevention. He is the MSM (Green, 2013), or the "gay" man at "increased risk" for HPV (Malan, 2012b). However, CANSA is cited as recommending the "HPV vaccine for men up to the age of 26, particularly those having sex with men" due to him being "17 times more likely to develop anal cancer" than a heterosexual man (Malan, 2012b). Even though sexual behaviour of MSM may not contribute to CC, this report allows this marginalized group representation because HPV exposure may place MSM at risk for anal cancer if they engage in anal penetrative sex.

A complicated representation of HPVV follows, however, when MSM are allowed to enter the debates in these reports. For, in arguing why boys should not be vaccinated, anal and oral cancers are relegated singularly as risks instead for MSM. The rationalization is based on essentialist assumptions of sexuality and sexual orientation, as illustrated in the article that quotes the Chairperson of National 
Advisory Group on Immunisation as saying, "Although oropharynx and anogenital cancers caused by HPV are increasingly common in men who have sex with men, it is too difficult to target this group when they are only nine years old" (Green, 2013). The problem with this mainstay perspective of health interventions targeting risky sex groups is the notion of needing to separate people on the basis of a partner's sex (i.e., differentiating MSM from heterosexual men). Thus, while the heterosexual man is constructed as being protected through the (monogamous) female partner being vaccinated, the MSM are, by implication, made diseased through being denied available vaccinations. MSM, with reference to HPV, are marginalized by not talking about them. As Charles (2014) has argued, promotional materials privilege heterosexuality, and the erasure of MSM makes them noncitizens. The newspaper quote by the Chairperson of National Advisory Group on Immunisation gives MSM a position of vulnerability within the essentialised framing of sexuality.

The sex-talk son is a teenage boy described in one news report entitled "Giving your son the cancer sex talk" (Lavender, 2013). He is at the age where his parents must inform him of the "importance of safe sex" (Lavender, 2013). Although this male subject should ideally be vaccinated, his parents are "too queasy to raise the issue" (Lavender, 2013). The sex-talk son is either on the verge of sexual discovery, or starting to have sex, and he is thus positioned as being in need of sex education. He may be completely unaware of HPV and CC, and he may end up becoming an unaccountable male. He is new to taking responsibility in sexual matters, as positioned by a naïve and anxious mother. After being confronted with the sex talk, he is positioned to decide what to do with that information because he is not being coerced or encouraged by the media or the government to take an active stance in CC prevention. The story, however, is framed as a problem for the parent in question because the dominant romantic discourse of sexual relations, in the parent's view, is incompatible with the risk discourse associated with the vaccine: "How do you approach a young man who has just fallen in love for the first time and suggest that he be vaccinated against an infection he might 'catch' from his beloved during certain sexual practices" (Lavender, 2013)?

Not only teen and adult men, but boys too receive mention in the news reports. First, the excluded boy represents young, school-aged boys who "don't fall in that group" of targeted individuals for HPVV (Stassen, 2014). This subject, referred to in four press reports, is "obviously involved in the transmission" (Mundell, 2007). Questions are raised around exclusion from HPV:

“[S]hould boys be vaccinated against HPV?" (Green, 2013)

"So why are boys not offered Gardasil?" (Lavender, 2013) 
"[But] why didn't they inoculate the boys too?" (Ridyard, 2010)

"So what is happening to boys - who are carriers of HPV ... ?" (Stassen, 2014)

The excluded boy is positioned as missing out on an opportunity to play a role in the prevention of CC. He hears about the vaccination programme from female classmates but may not even contemplate that CC prevention can involve him, or that, later in life, he can transmit the infection. This erases boys not only from the particular campaign, but also from possibilities for decision making about sexual health (Davies \& Burns, 2014). These reports, however, seem to explicitly aim at conscientising readers about the equal role of the male partner in the transmission of HPV.

The final younger male subject, identified in three articles is the boy saviour, who reflects the atypical subject position of getting vaccinated within the private healthcare system: "cervical cancer could, in theory, be wiped out. This is only achievable if every girl and boy has the jab" (Boseley, 2006). The boy saviour, similar to the disease-free partner and circumcised saviour, adopts a heroic stance as he and his parents rebel against the norm. They take action for a disease in which the boy may assume he has no role to play. $\mathrm{He}$ is constructed as brave, whereas girls, in opposition, get relegated to a potentially promiscuous but responsible positioning.

Poststructural feminism points to ascertaining which gender is included and which is excluded (Thompson, 2010). Applied to these news reports, even though a discourse of non-accountability has been identified in some articles, not all males are sidelined. Positions such as the conservative monogamist (disease-free partner), the new fashionable image of the "safe" circumcised saviour, and the brave activist position (boy saviour) are aligned with prevention. In these positionings, appropriate male actions include going for physical examinations and being circumcised, but vaccinations are still atypical interventions. The vagueness of medical exams recommended for men is in line with the practice of normalizing them for women, whereas men are not compelled to give their sexual health compulsive surveillance (Thompson, 2010). The unaccountable man (seven articles) and the circumcised saviour (six articles) received the most coverage, with the former suggesting a role of freedom and the latter, a role of protector. The lack of accountability is made possible because HPV infection in men can be asymptomatic, subclinical, and may present as genital warts (Giuliano, 2007), rather than encompassing the fatality characteristic of cancer.

A news report, though, might still introduce publicly invisible ideas such as the risks of MSM to HPV. If men are not vaccinated, they might need secondary prevention in 
the future for anal cancer, given the extent of the rising problem (Thompson, 2010). Thus, Pap smears for men might be necessary (Oon, Hanley \& Winter, 2010), because MSM cannot be targeted as a group as children (Stanley, 2012). Thus, reports have the potential to challenge ideas about those conventionally silenced such as MSM who are not addressed by health campaigns (Thompson, 2010).

\section{Female risk positions}

The at-risk woman (six articles) is a sexually active subject who is at an elevated risk of HPV infection and CC. This is a woman whose sexual decision making can place her in a position of risk and vulnerability. For example, Graham's (2006) article entitled "The silent killer" discusses low and high risk HPV types, along with noting lack of symptoms in precancerous stages. Once infected, risks extend beyond the virus to the internal bodily functioning, as presented in Mthethwa's (2006) article, wherein semen is constructed as dangerous because the high concentration of prostaglandins in semen increases cancer growth. The medical scientist quoted therein therefore recommends that women suggest condom usage: "this suggests that sexually active women who are at the risk of cervical or uterine cancer, should encourage their partners to wear a condom to prevent increased exposure to prostaglandins that might worsen their condition" (Mthethwa, 2006). Thus, as the primary target of HPV and CC campaigns, female sexual actions and biology are conceptualized as problem areas.

As early as 2001, the at-risk female positioning was counterpoised against an androcentric health system, but this was also racialized. Rural black women were reported as being most at risk because they presented late for treatment of CC, thus early screening needed implementation. At that time, women's health lacked governmental commitment, and the public screening policy was not implemented. This positioned woman as victims of an uncaring masculinist government. The at-risk woman is represented in opposition to the male-biased SA government of the time through a comment by the CANSA vice-president, who is quoted by Caelers (2001) as stating, "If men suffered from cervical cancer, the pap smear would be one of the 10 commandments".

The included schoolgirl (seven articles) is more "prone to (HPV-linked) cancer" than boys (Mundell, 2007). She receives free vaccinations (Green, 2013), thus is located in opposition to the excluded schoolboy. She is a young learner at primary school and may not yet be knowledgeable about sex and reproductive illnesses. Nonetheless, she receives vaccination for a disease she may develop only later in life once she becomes sexually active. She has to surrender to this protection, to which her parents have agreed, for a cause of which she is unaware. Her fellow girl classmates also receive these vaccinations, whereas her boy classmates do not. She may then make sense of this by concluding that girls are responsible for this disease 
and therefore its prevention. This ideal positioning for a woman conforms to the historical trend of female bodies being problematized and medicalised as natural containers of disease.

The female risk positions illuminate conceptual work in the critical literature. Thompson (2010) argues how paternalism and protection work collectively to propagate the subject positions allocated to women. The concept of risk, linked to women, absolves male accountability for sexual health (Thompson, 2010). This is demonstrated by the position of vulnerability accorded naturally to females. The risk approach can be considered a form of governance over women's bodies (Peterson, 1997). By providing females with guidelines and responsibilities, a woman's sexuality and sexual actions are organized and regulated. Young girls being subjected to vaccinations indicates how medicalization of their bodies start at a very early age (Vardeman-Winter, 2012). Moreover, the subject position is stigmatized as one of being responsible and promiscuous, whereas males may be positioned either as not promiscuous or as safe from consequences of being so. This conforms to masculinist ideals of unquestioned heterosexism where female bodies are sites of vulnerability and anxiety (Mishra \& Graham, 2012).

In the at-risk position, a woman is compelled to be aware of what her body is doing because she is the owner of the disease, as shown in the quote presented from Mthethwa's (2006) news report. In the at-risk position, the female body is regulated and accorded with accountability. Such a construction, however, assumes western-style behavioural empowerment - she may be the owner of the disease, but, in many local contexts, she may seldom be the owner of her body.

\section{Parents}

Parental subject positions in the texts include not only a decision-making position, but also a position of responsibility (Lavender, 2013). Two parental subject positions emerge: the gatekeeping mother and the tongue-tied parent.

The gatekeeping mother, appearing only in an opinion piece, "Vaccine talk pricked my conscience" presents a parent who has been exposed to "vaccine talk" by others and the media: "my son told me all the girls in his year had been vaccinated against HPV" (Ridyard, 2010). At first, she was overprotective, being against HPVV and used capitalism as an excuse: "Screw you, money-grabbing pharmaceutical companies ... You're not making money from MY boys" (Ridyard, 2010). The position of anger and territoriality then shifts to admitting that "[she] was wrong" on realizing that vaccinations will save lives. This parent is thereafter no longer against HPVV and agrees to consent to her son receiving it. The change in position is pedagogically toned: 
"Vaccination is vital; it's far cheaper and far more effective than treatment, and there is the ultimate achievable hope of eradicating such diseases, just like deadly, devastating smallpox was eradicated, like polio will be soon ... it will be if less parents are as feckless as I was." (Ridyard, 2010)

This confessional seems well-placed within a newspaper to give voice to a debated issue wherein dominant discourses exclude vaccination for boys.

The gatekeeping mother is a guardian and a key decision maker. She is confronted with a public health agenda of girls and not boys getting vaccinated, but as a custodian of her son's health, she first considers possible hidden agendas (such as greed from pharmaceutical companies) before she goes against the status quo by consenting to HPVV for her sons. Even though she first takes the position of anger and resistance, she changes her mind to position herself as a social rescuer through being justified to allow her son to be vaccinated. The reader in turn is enticed to adopt a subject position of being educated and to interrogate resistance like the mother in the text. The mother herself has to be "pricked" to be transformed into a good citizen and good parent. Empirical research (Rickert et al, 2014) confirms that intent (i.e., being "pricked") should be the focus of interventions if parents are to allow sons to be vaccinated.

Relative to the gatekeeping mother who has young sons, the tongue-tied parent has teenage boys. "[T]ongue-tied parents" is the group into which the writer (a mother) positions herself and the father of her sons, and this subject appears in a single article (Lavender, 2013). The mother critically comments on how Michael Douglas talked about his throat cancer (caused by HPV). As a mother of two sons, this cultural reference triggered anxieties in her, thus she adopts an avoidant position: "I do not know, nor wish to know, about the types of sex they may engage in" (Lavender, 2013). This subject is concerned that her sons may contract the virus and wants them to undergo private HPVV. Despite this, she does not know how to serve as a health promoter in the "cancer sex talk": "How do you approach a young man who has just fallen in love for the first time and suggest that he be vaccinated against an infection he might catch from his beloved during certain sexual practices?" (Lavender, 2013). Once again, the mother is positioned as one who should take action. The mother's adamant refusal, however, to take on the socially sanctioned position of health educator for a male child means that the boy will grow up to adopt the unaccountable man position. The refusal in the statement, "I do not know, nor wish to know, about the types of sex they engage in" (Lavender, 2013) has implications for health decision making. The notion of a "cancer sex talk" belongs to sex education discourse. However, this representation of a special conversation under the management of the mother is problematic (Wilbraham, 2004). Furthermore, linking sex to romance and intimacy complicates uptake of HPVV. HPVV thus becomes a social,

PINS [Psychology in Society] 52 • 2016|60 
anxious, and moral encounter, unlike other more 'normalized' vaccines. Here, the biological fact of sexual transmission in the context of HPV transforms the body from a biological apparatus to a social object that is couched in local and cultural meanings within the grander biopolitical regime.

The tongue-tied parent gives her sons neophyte positions in sexual health. She is highly enlightened about HPV and its consequences, believing boys should be vaccinated too, yet she is anxious and avoidant about discussing this with her sons. Her subjectivity revolves around the awkward decision about pedagogical action. She may be held back by ideas of CC as a woman's illness and might be wary of how her sons will take up her sudden concern. This may cause her never to even go through with this discussion. Another major problem here is the mother's denial and embarrassment of her son's possible sexual activities. By using the term "in love", the position further constructs the idea that the son is only going to have sex when he is in love, or because he is in love. Sex, or at least the earliest experiences of it, is thus romanticized.

The intimacy discourse of sex as moral justification for male vaccination has been used (Luyten et al, 2014), yet this dominant construction serves as a barrier for action and excludes the realistic possibility that sex may be experienced outside of the context of emotional and romantic intimacy. The parent-consumer must engage with sexual enlightenment. As Thompson (2010) argues, children's health is seen as an intricate part of motherhood. The press reports give voice to mothers instead of fathers, implying that fathers' role in their children's health is silenced while the mother's role is given prominence, an echo of sex education media texts (Wilbraham, 2004).

\section{Professionals}

The professional activist supports the inclusion of males in the prevention of CC. Appearing in eight articles, these role players include healthcare professionals such as gynaecologists, academics, virologists, and clinic directors. They adopt a knowledgeable and pedagogical position, calling for greater male responsibility in the prevention of CC:

"I think it is important to consider boys as equal players in that process', says ... director of medical gynaecologic oncology at Fox Chase Cancer Centre in Philadelphia." (Mundell, 2007)

“Virus a danger to both sexes' - docs.” (Nkosi, 2014)

"'The broader the cover, the better. It is time to start a campaign in vaccinating males,' [the medical practitioner] said." (Nkosi, 2014) 
"Specialist medical practitioners in the private sector are pushing for men to be vaccinated." (Nkosi, 2014)

"He [the medical practitioner] said the government should not balk at the price providing vaccines for men." (Nkosi, 2014)

"While young girls are the focus of HPV vaccine campaigns, [the virologist] said boys should not be forgotten about in the HPV discourse." (Skade, 2011)

"British doctors have said it should be given to all boys and girls between the ages of nine and 11, before they start sexual activity." (Caelers, 2006)

These subjects acknowledge, however, that "it is difficult to get men to vaccinate for a disease predominant in women" (Nkosi, 2014). Notwithstanding this epidemiological "fact", the inclusion of interviews with professionals allows press reports to engage vibrantly with the view that male persons also need to be vaccinated against HPV.

\section{Organizations}

Organizations may assume one of two distinct positions: the pro-male vaccine organization or the fiscal-savvy organization. The former appears in two articles and includes pharmaceutical companies, CANSA, or the SA Dental Association. Similar to the individual activist, these respected organizations adopt a position of advocacy, thus they are made up of knowledge influentials in HPV transmission. The pro-male vaccine organization serves to "recommend the HPV vaccine for girls and boys" and expresses "concerns about the roll-out being limited to younger, school-going girls" (Stassen, 2014). Here, this is about health advocacy for ensuring equality in health, both nationally and globally (Stassen, 2014). Another article, in the context of a warning from the SA Dental Association that oro-pharyngeal cancers develop from oral sex, cites a professor at a university's school of dentistry as having stated that the HPVV can prevent oral cancers, with the report adding that the SA Dental Association "has [therefore] launched an educative campaign" (McLea, 2011). The recommendations, through the SA Dental Association's pro-vaccine position, are supplemented by subtext in the editorial commentary that these recommendations are unrealistic in a fiscally-challenged country: "The US Centres for Disease Control and Prevention has also recommended young boys receive the vaccine, which costs about R2 500 in South Africa" (McLea, 2011).

On the other hand, the fiscal-savvy organization, appearing in two articles, represents the SA government and the National Advisory Group on Immunisation who advocate a girls-only national vaccination programme (Stassen, 2014). As reported in the Mail \& Guardian, "the government will provide free HPV vaccines to the poorest $80 \%$ of 
9-and10-year old schoolgirls - but not boys" (Green, 2013). While not taking a stance of anti-male vaccination per se, these organizations feed into the cost-saving rhetoric: "it just isn't cost-effective to provide the vaccines to boys at this stage" (Green, 2013). The fiscal-savvy organization determines what the macrosystem will do in terms of a global health issue. Financial consequences are considered the single most important determinant. Preconceived notions of $\mathrm{CC}$ being only a female responsibility may deter them from recommending male vaccinations.

Young girls are promised better health if vaccinated, and are thus managed on a macroscale by the governmental vaccine campaign. The pro-male vaccine organization recognizes and questions this large-scale exclusion of boys from campaigns. The fiscal-savvy organization, on the other hand, may recognize the importance of male vaccination, but this is not translated into action as practicality and cost-effectiveness take priority. This is a case in point of Thompson's (2010) statement that a country's government can unknowingly continue to propagate paternalistic values. Furthermore, the position of the fiscal-savvy organization reinforces structural culpability because, following the argument of Luyten et al (2014), policies about HPVV, which are argued to be morally justified for both boys and girls, cannot be ethically based on cost-effectiveness. This organization's agency illustrates how biopolitics links with sex selectivity.

\section{Networks of relationships}

Networks of relationships also need analytic consideration. The predominant relationships cover sexual transmission, that is, those between the at-risk woman and her sexual partners (the unaccountable man, the disease-free partner, and the circumcised saviour). The unaccountable man jeopardizes the at-risk woman's health, whereas the disease-free partner and the circumcised saviour positions guard it. In the relationship between the professional activist and the patient (either male or female), the professional as authority is willing to provide services that can keep the patient safe from HPV. Nonetheless, the patient or the patient's parent (in the cases of the excluded boy, the boy saviour, and the included schoolgirl) still decides whether this happens or not. Thus, the additional relationship between the medical professional and the parent becomes key: the parent will either oppose or accept the professional recommendation. Ultimately, the parent controls whether the excluded boy will get vaccinated or not. Next, the relationships between parents and their children create decision-making or educational roles. Besides allowing the vaccination, the parent should also provide the cancer sex-talk, placing her in an active position in both instances. Lastly, relationships are set up through the fiscal-savvy organization's antagonistic positioning towards the professional activist and the pro-male vaccine organization. One side is not supportive of the implementation of a national vaccine campaign for boys and the other side lobbies for this implementation. A final conflictual position is set up between the gatekeeping 
mother who initially refuses to have her sons vaccinated and the pro-male vaccine organization that she constructs as financially greedy. She rejects the initial subject position but needs to become an educated neoliberal consumer of health information (Briggs \& Hallin, 2007).

These networks of relationships serve as empirical illustration of Briggs and Hallin's (2007) theory of bio-communicability wherein health news texts reveal positional intersections of journalists, medical professionals, researchers, policymakers, and activists. So, in how texts address the reader as a particular type of person (Wilbraham, 2004), including as a consumer (Briggs \& Hallin, 2007), subject-positioning analysis in the sample has revealed the primary addressee of CC prevention discourse to be a female adult decision maker who should be informed and then take action based on that information. This is part of the neoliberal project (Charles, 2014). The addressee is a woman who may be seeking information on a disease she wants to know more about (Thompson, 2010). Furthermore, in the reported national school campaign, it is not just individual at-risk women who become addressees, but also mothers of girls, and this mother has to provide consent or take action about vaccination.

\section{Conclusion}

Although this study was not located in a paradigm that infers effects of media messages, it illuminates the public portrayal of CC prevention in a highly selective media sample. The search strategy might have contributed to the limited sample because keywords were directed at CC specifically (given the aims of the broader project), and this search therefore excluded news articles that might have reported purely on HPV and men, instead of HPV and CC. However, the limited number of reports that mentioned the male role in CC prevention could provide messages to male readers that they do not have a role in transmission of oncogenic HPV. In other words, the relative invisibility of men in newspaper reports about CC reinforces the notion of HPV as a female problem, despite biological evidence pointing to a male role in HPV transmission. Notwithstanding this, poststructural readings may use small samples, and such readings indicate a sociopsychological problematization that confers different positionings to men (and other role players), each with its own bodily responsibilities and politicized subjectivities. As Thompson (2010) points out, the barriers preventing male engagement in health and health communication are discursive; subject positions in heterosexist ideologies do not get questioned in the discourse about the biopolitical rescue of the female body.

Nevertheless, the press content indicates moments in which the male role in CC is put under the social spotlight. Newspapers still interrogate representations of dominant discursive positionings, as this textual analysis has shown. This is done primarily through the representations of professionals. Medical scientists and public health activists, 
when interviewed, question the exclusion of boys from the vaccination campaign in SA. The position of the pro-male vaccine organization adds to this activist voice by recommending vaccinating both sexes and criticizing campaigns that exclude young boys. This is a gap for media campaigns to exploit.

The problem with discursive positions (such as the fiscal savvy organization touting the social viewpoint that $\mathrm{CC}$ is a female responsibility) is that a particular positioning in turn assigns the solution for women to take action as the holders of CC. Focus on women taking individual responsibility deflects from the political purpose of vaccination; social responsibility should be taken up by a public health system that should engage with men's roles in the transmission and prevention of CC. Instead, men are predominantly allocated a position of freedom (the unaccountable man) or that of protecting female sex partner (circumcised saviour). This contributes to CC remaining within the domain of women's health. Positioning the man as unaccountable may appear quantitatively (in terms of its representation in the highly selective sample) as an interpretation that should be bypassed; however, this positioning echoes men's lives on the ground, as was indicated in Maree et al 's (2011) survey where none of the 980 men possessed knowledge about the HPV-CC connection. Opportunity for intervention is further implied in the coverage of the boy saviour positioning. When encouraged, this position reflects a point of resistance against the dominant exclusionary representation of men. Combined with activist positions of professionals and the pro-male organization, such representations reflect sites for public health interventions that are able to give voice and moral action to men and boys.

Thus, CC should be conceptualized not merely as a health issue faced by individual women, but as a social issue faced by all communities and genders. Sociopolitical meanings of being a man or woman (e.g., as unaccountable or as at-risk) through non-essentialised identities (Vardeman-Winter, 2011) need transformation in health campaigns. Larger social and structural responsibility needs to address the biology of male transmission of oncogenic HPV. Individualization, offered by the public health system and the fiscal-savvy organization in a top-down way, is problematic, but as soon as at-risk women govern their bodies (properly), they engage in bottom-up processes of self-governmentality that accords them healthy citizenship (Davies \& Burns, 2014). This is consistent with health media texts presenting discourse about HPVV through neoliberal techniques of (gendered) governmentality (Briggs \& Hallin, 2007; Charles, 2014; Davies \& Burns, 2014).

The at-risk woman in the news articles draws on the traditional medical risk paradigm that draws on factors such as multiple partners or non-monogamy. This representation, however, in line with the rationalistic basis of this rhetoric, ignores local contextual 
challenges. The western biomedical information contained in the press articles ignores the disempowered sex lives of many female persons in SA. The press articles ignore local features such as sexual abuse, rape, and age-discordant relationships, features which prevent women from making autonomous sexual health decisions. In other words, in such a context, the vaccination, as discovered by Katz et al (2013), can provide girls greater control over their sex lives.

The parent subject positions in the findings have implications for the entry point for health education and vaccination promotion of both boys and girls. Mothering includes a gatekeeping role because mothers decide on consent and uptake. In particular, if she initially holds a tongue-tied parent position, which is a role in which sexual realities get ignored, she should thereafter adopt a less embarrassed position by accepting the possibility that adolescents may have sex. The tongue-tied parent position can also be challenged by involving the father of her children. Like the resistant or angry gatekeeping mother role, the tongue-tied parent also requires conscientization. One solution offered by Botha and Richter (2015) is that female caregivers need to be involved in the national CC screening programme and when this occurs, vaccination of children requires health promotion linking here. This can particularly work in SA because mothers and grandmothers, in making health decisions for children, can serve as educators and role models (Francis \& Katz, 2013). Thus, female caregivers should be the primary target of health education about CC, and the screening examination (Botha \& Richter, 2015) provides a discursive opportunity for interrogating subject positions.

\section{References}

Abdelmutti, N \& Hoffman-Goetz, L (2009) Risk messages about HPV, cervical cancer, and the HPV vaccine Gardasil: A content analysis of Canadian and U.S. national newspaper articles. Women and Health, 49(5), 422-440.

Balachandran, I (2011) Human papillomavirus and pap smear: A review. American Journal of Lifestyle Medicine, 6(31), 31-44.

Botha, M H \& Richter, K L (2015) Cervical cancer prevention in South Africa: HPV vaccination and screening both essential to achieve and maintain a reduction in incidence. South African Medical Journal, 105(1), 33-35.

Branson, C F (2012) "I want to be one less": The rhetoric of choice in Gardasil ads. The Communication Review, 15(2), 144-158.

Briggs, C L \& Hallin, D C (2007) The neoliberal subject and its contradictions in news coverage of health issues. Social Text, 25(4), 43-66. 
Casciotti, D M, Smith, K C, Andon, L, Vernick, J, Tsui, A \& Klassen, A C (2014) Print news coverage of school-based human papillomavirus vaccine mandates. Journal of School Health, 84(2), 71-81.

Cates, J R, Diehl, S J, Crandell, J L \& Coyne-Beasley, T (2014) Intervention effects from a social marketing campaign to promote HPV vaccination in preteen boys. Vaccine, 32(33), 4171-4178.

Charles, N (2014) Injecting and rejecting, framing and failing: The HPV vaccine and the subjectification of citizens' identities. Feminist Media Studies, 14(6), 1071-1089.

Davies, C \& Burns, K (2014) Mediating healthy female citizenship in the HPV vaccination campaigns. Feminist Media Studies, 14(5), 711-726.

Denny, L (2006) Prevention of cervical cancer. South African Health Review, 20(1), 333-346.

Denny, L (2010) Cervical cancer in South Africa: An overview of current status and prevention strategies. Continuing Medical Education, 28(2), 70-73.

de Vries, L (2014) Representation of cervical cancer in South African newspapers. Unpublished Honours research essay. University of Johannesburg, Johannesburg.

Dillner, J \& Brown, D R (2004) Can genital tract human papillomavirus infection and cervical cancer be prevented with a vaccine? Expert Reviews in Molecular Medicine, 6(9), 1-21.

Donahue, K L, Stupiansky, N W, Alexander, A B \& Zimet, G D (2014) Acceptability of the human papillomavirus vaccine and reasons for non-vaccination among parents of adolescent sons. Vaccine, 32(31), 3883-3885.

Driedger, S M (2007) Risk and the media: A comparison of print and televised news stories of a Canadian drinking water risk event. Risk Analysis, 27(3), 775-786.

Dunne, E F \& Markowitz, L E (2006) Genital human papillomavirus infection. Clinical Infectious Diseases, 43(5), 624-629.

Foucault, M (1978) The history of sexuality, Volume 1: An introduction. New York: Vintage Books (1976-French).

Francis, S A \& Katz, M L (2013) The HPV vaccine: A comparison of focus groups conducted in South Africa and Ohio Appalachia. Maternal and Child Health Journal 17(7), 1222-1229.

Gavey, N (1989) Feminist poststructuralism and discourse analysis: Contributions to feminist psychology. Psychology of Women Quarterly, 13(4), 459-475.

Giles, D (2003) Media psychology. Mahwah: Routledge. 
Giuliano, A R (2007) Human papillomavirus vaccination in males. Gynecologic oncology, 107(2), S24-S26.

Habel, M A, Liddon, N \& Stryker, J E (2009) The HPV vaccine: A content analysis of online news stories. Journal of Women's Health, 18(3), 401-407.

Harper, E A \& Rail, G (2011) Contesting "silhouettes of a pregnant belly": Young pregnant women's discursive constructions of the body. Aporia, 3(1), 5-14.

Harries, J, Moodley, J, Barone, M A, Mall, S \& Sinanovic, E (2009). Preparing for HPV vaccination in South Africa: Key challenges and opinions. Vaccine, 27(1), 38-44.

Hook, D (2004) Foucault, disciplinary power and the critical pre-history of psychology, in Hook, D (ed) (2004) Critical psychology. Cape Town: UCT Press.

HPCSA (2014). Cancer vaccination campaign under way.http://www.hpcsa-blogs.co.za/ cancer-vaccination-campaign-under-way

Jäger, S \& Maier, F (2009) Theoretical and methodological aspects of Foucauldian critical discourse analysis and dispositive analysis, in Wodak, R \& Meyer, M (eds) (2009) Methods of critical discourse analysis. London: Sage.

Katz, I T et al (2013) A qualitative analysis of factors influencing HPV vaccine uptake in Soweto, South Africa among adolescents and their caregivers. PLoS One, 8(8), 1-7.

Lowndes, C M (2006) Vaccines for cervical cancer. Epidemiology and Infection, 134(1), $1-12$.

Lupton, D (1997) Foucault and the medicalisation critique, in Peterson, A \& Bunton, R (eds) (1997) Foucault, health, and medicine. London: Routledge.

Luyten, J, Engelen, B, \& Beutels, P (2014) The sexual ethics of HPV vaccination for boys. HealthCare Ethics Committee Forum: An Interprofessional Journal on Healthcare Institutions' Ethical and Legal Issues, 26(1), 27-42.

Maree, J E, Wright, S C D, \& Makua, T P (2011). Men's lack of knowledge adds to the cervical cancer burden in South Africa. European Journal of Cancer Care, 20(5), 662-668.

Mishra, A \& Graham, J E (2012) Risk, choice and the "girl vaccine": Unpacking human papillomavirus (HPV) immunisation. Health, Risk \& Society,14(1), 57-69.

Okonofuya, F (2007) HPV vaccine and prevention of cervical cancer in Africa. African Journal of Reproductive Health, 11(2), 7-12.

Oon, S F, Hanly, A \& Winter, D C (2010) Pap smears for men: A vision of the future? Irish Journal of Medical Science, 179(3), 459-462. 
Papadopoulos, D (2008) In the ruins of representation: Identity, individuality, subjectification. British Journal of Social Psychology, 47, 139-165.

Parker, I (1992) Discourse dynamics: Critical analysis for social and individual psychology. London: Routledge.

Peterson, A (1997) Risk, governance and the new public health, in Peterson, A \& Bunton, R (eds) (1997) Foucault, health, and medicine. London: Routledge.

Rickert, V I, Auslander, B A, Cox, D S, Rosenthal, S L, Rickert, J A, Rupp, R \& Zimet, G D (2014) School-based vaccination of young US males: Impact of health beliefs on intent and first dose acceptance. Vaccine, 32(17), 1982-1987.

Shi, L et al (2007) Gardasil: Prophylactic human papillomavirus vaccine development from bench top to bed-side. Clinical Pharmacology and Therapeutics, 81(2), 259-264.

Stanley, M (2012) Perspective: Vaccinate boys too. Nature, 488(7413), S10-S10.

Thompson, M (2010) Who's guarding what? A poststructural feminist analysis of Gardasil discourses. Health Communication, 25(2), 119-130.

Vardeman-Winter, J (2012) Medicalization and teen girls' bodies in the Gardasil cervical cancer vaccine campaign. Feminist Media Studies, 12(2), 284-301.

Weedon, C (1987) Feminist practice and poststructuralist theory. New York: Basil Blackwell.

Wilbraham, L (2004) Discursive practice: Analysing a Lovelines text on sex communication for parents, in Hook, D (ed) (2004) Critical psychology. Cape Town: UCT Press.

Wright, J (2003) Poststructuralist methodologies: The body, schooling, and health, in Evans, J, Davies, B \& Wright, J (eds) (2003) Body knowledge and control: Studies in the sociology of physical education and health. London: Routledge.

\section{Newspaper articles in sample}

Beaver, T (2013, August 30) Queuing to save lives. The Witness, p 9.

Bodibe, K (2013, November 29) SA has big HIV challenge. The New Age, p 17.

Boseley, S (2006, February 2) Can you catch cancer? Mail and Guardian, p 9.

Caelers, D (2001, February 21) The cancer that need not kill. The Star, p 10.

Caelers, D (2006, January 26) Cancer vaccine approval urged. Cape Argus, p 12.

Early detection can beat cervical cancer (1998, December 10) The Natal Witness, p 19. 
Giving boys vaccine for cervix cancer will save lives (2007, January 28)

Sunday Times, $\mathrm{p} 15$.

Graham, D (2006, May 31) The silent killer. The Citizen, p 5.

Grange, H (2011, November 23) Oral sex can trigger cancer. The Star, p 16.

Grant-Marshall, S (2010, September 22) Facing up to threat of disease.

Business Day, p 3.

Green, A (2013, June 13) Life saving cancer vaccine will be difficult to implement.

Mail and Guardian, p 34.

Lavender, C (2013, June 16) Giving your son the cancer sex talk. Sunday Times, p 18.

Malan, M (2012a, July 26) The chief who lit a cultural fire. Mail and Guardian, p 1.

Malan, M (2012b, November 29) Cervical cancer can be prevented.

Mail and Guardian, p 1.

Masoetsa, M.(2011, July 15) Govt tells men to take a cut. The Citizen, p 5.

McLea, H (2011, October 5) Oral sex not as safe as it's made out to be. The Times, p 6.

Mkize, V (2013, August 28) The vaccine that helps prevent cervical cancer. The Star, p 2.

Mthethwa, B (2006, September 10) Semen found to increase the risk of cervical cancer.

Sunday Times, $\mathrm{p} 13$.

Mundell, E J (2007, May 30) Cervical cancer: Now debate rages on whether to give boys the shot too. Business Day, p 4.

Naran, J (2007, July 22) Giving HIV infection the snip. Sunday Tribune, p 4.

Nkosi, N (2014, March 7) Campaign for male vaccination mooted. Sowetan, p 10.

Ord, L (1999, April 7) Millions miss out on cancer checks. Daily News, p 8.

Ridyard, J (2010, October 25) Vaccine talk pricked my conscience. The Citizen, p 13.

Skade, T (2010, December 13) Teen takes medical circumcision route to stay HIVnegative. The Star, p 2.

Skade, T (2011, November 18) Virus that causes cervical cancer increases risk of HIV. The Star, $\mathrm{p} 3$.

Stassen, W (2014, March 12) Fears raised over HPV jab. The Star, p 5. 